\title{
移流モデルによる短時間降雨予测手法の検討 \\ Investigation of Short-Term Rainfall Prediction \\ Method by a Translation Model
}

$\begin{array}{llll}\text { 京都大学工学部 } & \text { 正員 } & \text { 椎葉 } & \text { 充晴 } \\ \text { 京都大学工学部 } & \text { 正員 } & \text { 高棹 } & \text { 环馬 } \\ \text { 京都大学大学院 } & \text { 学生員 } & \text { 中北 } & \text { 英一 }\end{array}$

1.はじめに

本研究は,レーダ雨量計によって時々刻々得られる面的な降雨強度データを外挿して, 2 3 時間先 までの降雨強度を予測する手法を提案し，その適用性を検討するるのである。

レーダ雨量計を用いた降雨予測手法はすでにらくつか提案されており, 予測と用いる移流べクトルの 設定方法の違いによる大倉ら ${ }^{1)}$ の分類によると，(1) 運動学的方法(高層風による移流 ) 2 ， (2)変形テン ソルによる方法 ${ }^{3)}$ ，(3)カルマンフィルターによる方法 ${ }^{4)}$ ，(4)相互相関関数飞よる方法 ${ }^{5)}$, (5) 重心の移動 飞着目する方法 ${ }^{6)}$ などがあり, さらに大倉らによる(6)関連係数を用いる雨域追跡法 ${ }^{1)}$ がある。最近, 筆 者らは(7)重みつを相関法 ${ }^{7)}$ を検討した。

本研究で検討する降雨予測手法は，予測飞用いる移流べクトルを位置座標の一次式で設定するるので， 雨域の平行移動, 回転, せん断的歪み, 膨張などを考虑するととがでをる。平行移動に限らないこのよ うな雨域の変形を考慮する方法についてはすでに下垣ら゙)が検討しているが, 座標系で議 論しているために変形のパラメタを求めるのに非線形探索問題を解く必要が生じている。変形テンソル 法は, 雨域変形の点対を人為的に与えるてとでての非線形探索問題を避けたものである。こてで検討す る方法では Euler 座標采を用いるため, 雨域変形のパラメ夕を求める問題を線形最小二乗推定問題と して定式化するととが可能となり，計算機によって容易に解けるといら利点を持っている。

\section{2、移流モデルとその同定・予測の方法}

2.1 移流モデル

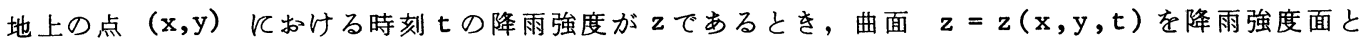
よぶ。降雨予測はこの降雨強度面の変化の予測飞他ならない。現在のとてろ, 定性的議論は別として, 定量的飞実時間予測飞役立つょうな気象力学的根拠をもった降雨強度変化の支配方程式は得られていな いよらである。そこで, 本研究では, 立平ら ${ }^{2)}$ にる簡単な移流モデル

$$
\frac{\partial z}{\partial t}+u \frac{\partial z}{\partial x}+v \frac{\partial z}{\partial y}=w
$$

を用いる。さらに, 移流べクトル $(\mathrm{u}, \mathrm{v})$, 発達・衰弱項 wは, 位置 $(\mathrm{x}, \mathrm{y})$ の一次式として,

$$
\mathrm{u}=\mathrm{c}_{1} \mathrm{x}+\mathrm{c}_{2} \mathrm{y}+\mathrm{c}_{3}, \quad \mathrm{v}=\mathrm{c}_{4} \mathrm{x}+\mathrm{c}_{5} \mathrm{y}+\mathrm{c}_{6}, \quad \mathrm{w}=\mathrm{c}_{7} \mathrm{x}+\mathrm{c}_{8} \mathrm{y}+\mathrm{c}_{9}
$$

と近似されるものとする。乙てで, $c_{1}, \ldots, c_{9}$ は推定するべをパラメタである。

2.2 パラメタの同定法

レーダ雨量計の観測域に含まれる長方形領域をとり，それを $\Delta \mathrm{x} \cdot \Delta \mathrm{y}$ の長方形メッシニに分割する ものとし, $i=1, \ldots, M, j=1, \ldots, N, k=0,-1, \ldots,-k-1$ kつ々て

$$
x_{i}=i \Delta x, \quad y_{j}=j \Delta y, \quad t_{k}=k \Delta t, \quad z_{i j k}=z\left(x_{i}, y_{j}, t_{k}\right)
$$

と表わするのとする。ただし， $\Delta \mathrm{t}$ 時間間隔であり， M, $\mathrm{N}$ はそれぞれ $\mathrm{x}$ 方向，y方向のメッシュ数， $(\mathrm{K}+1) \Delta \mathrm{t}$ はパラメタ同定K使用する過去のデータの長さである。点 $\left(\mathrm{x}_{\mathrm{i}}, \mathrm{y}_{\mathrm{j}}\right)$, 時刻 $\mathrm{t}_{\mathrm{k}}$ の偏微分を

$$
\left[\frac{\partial z}{\partial t}\right]=\frac{z_{i j(k+1)^{-z}} i j(k-1)}{2 \Delta t},\left[\frac{\partial z}{\partial x}\right]=\frac{{ }^{z}(i+1) j k^{-z}(i-1) j k}{2 \Delta x},\left[\frac{\partial z}{\partial y}\right]=\frac{z_{i(j+1) k^{-z}}(j-1) k}{2 \Delta y}
$$


で近似し，

$$
\nu_{i j k}=-\left[\frac{\partial z}{\partial t}\right]-\left\{\left(c_{1} x_{i}+c_{2} y_{j}+c_{3}\right)\left[\frac{\partial z}{\partial x}\right]+\left(c_{4} x_{i}+c_{5} y_{j}+c_{6}\right)\left[\frac{\partial z}{\partial y}\right]-\left(c_{7} x_{i}+c_{8} y_{j}+c_{9}\right)\right\}
$$

と秋く。てれまでに述べた近似が妥当であり, バラメタ $c_{1}, \ldots, c_{9}$ が正しく同定されれば, $\nu_{i j k}$ は ○となるべをるのである。ょって

$$
J_{c}=\sum_{k=-K}^{-1} \sum_{i=1}^{M} \sum_{j=1}^{N} \nu_{i j k} 2
$$

を最小にするように $c_{1}, \ldots, c_{9}$ を推定するととにする。 $\nu_{i j k}$ は $c_{1}, \ldots, c_{9}$ の一次式であるから，

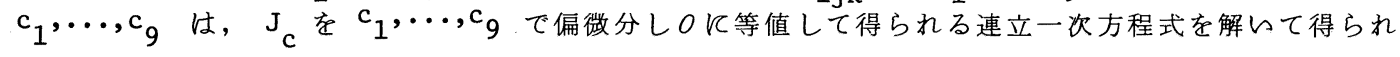
る。

実際の計算は次のようにすると，記憶容量の点でも分析の上でる有利である。まず，(5)式を未知パラ メタ $\underline{c}=\left(c_{1}, \ldots, c_{n}\right) \quad(n=9)$ の観測式とみなして,

$$
a_{i j k}^{1} d_{1} c_{1}+a_{i j k}^{2} d_{2} c_{2}+\ldots+a_{i j k n n}^{n} d_{n} c_{i j k}-v_{i j k}
$$

の形で考える。ただし， $\mathrm{d}_{\mathrm{p}}$ は(2)式でパラメタ $\mathrm{c}_{\mathrm{p}}$ をとり除くとを である。 $a_{i j k}^{1}, \ldots, a_{i j k}^{n}, b_{i j k}$ はそれぞれ(5)式中の対応する係数である。てのとを， J t最小にす るパラメタ $\subseteq$ は, 平方根情報フィルター (SRIF) ${ }^{8)}$ によって求められる。詳細は省略して手順だけ述べ ておく。以下では $\mathrm{m} を \mathrm{M} \cdot \mathrm{N} \cdot \mathrm{K}$ の約数とする。

(i) $(\mathrm{n}+\mathrm{m}) \times(\mathrm{n}+1)$ 次の行列 $\mathrm{S}$ を用意し，その上 $\mathrm{n}$ 行をOとおく。また， J を をとよく。

(ii) 各メッシニKついて $a_{i j k}, \ldots, a_{i j k}^{n}, b_{i j k}$ を計算し, s の $n+1$ 行目以降飞次々と追加する。

$\mathrm{S}$ の行数が $\mathrm{n}+\mathrm{m}$ 《なったら初めの $\mathrm{n}$ 列が上三角行列になるよらに SK Householder 変換を施 こした後

$$
\mathrm{J}_{\mathrm{c}}:=\mathrm{J}_{\mathrm{c}}+\sum_{i=\mathrm{n}+1}^{\mathrm{n}+\mathrm{m}} \mathrm{s}_{\mathrm{i},(\mathrm{n}+1)^{2}}
$$

とする。こてで,:=は右辺の值を左辺の変数の值とするととを意味する。

(iii)すべてのメッシュについて処理が終るまで(ii)を繰り返し, 最後に連立一次方程式

$$
\sum_{j=i}^{n} s_{i, j} c_{j}=s_{i, n+1}, \quad i=1, \ldots, n
$$

を後退代入によって解けば求める られている。

参考のため, Householder 変換と(9)式を解くFORTRAN77 によるプログラムを本文末に示す。

2.3 降雨予測の方法

同定されたパラメタが2〜3時間先まで持続すると仮定して将来の降雨強度を予測する。予測計算は 特性曲線の逆追跡による。(7)式で導入した係数 $d_{p}$ も含めて, 移流モデル(1), (2)の特性曲線が従ら微分 方程式は,

$$
\begin{aligned}
& \frac{d}{d t} x(t)=d_{1} c_{1} x(t)+d_{2} c_{2} y(t)+d_{3} c_{3} \\
& \frac{d}{d t} y(t)=d_{4} c_{4} x(t)+d_{5} c_{5} y(t)+d_{6} c_{6} \\
& \frac{d}{d t} z(t)=d_{7} c_{7} x(t)+d_{8} c_{8} y(t)+d_{9} c_{9}
\end{aligned}
$$

で与えられる。

よって, 時刻 $\mathrm{t}_{\mathrm{J}}=\mathrm{J} \Delta \mathrm{t}(\mathrm{J}>0)$ の位置 $\left(\mathrm{x}_{i}, \mathrm{y}_{j}\right)$ での降雨強度 $\mathrm{z}\left(\mathrm{x}_{i}, \mathrm{y}_{j}, \mathrm{t}_{\mathrm{J}}\right)$ は次の手順で求められ 
る。

(i) $x\left(t_{J}\right)=x_{i}, y\left(t_{J}\right)=y_{j}$ とおく。

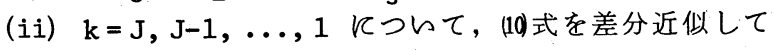

$$
\begin{aligned}
x\left(t_{k-1}\right) & =x\left(t_{k}\right)-\left(d_{1} c_{1} x\left(t_{k}\right)+d_{2} c_{2} y\left(t_{k}\right)+d_{3} c_{3}\right) \Delta t \\
y\left(t_{k-1}\right) & =y\left(t_{k}\right)-\left(d_{4} c_{4} x\left(t_{k}\right)+d_{5} c_{5} y\left(t_{k}\right)+d_{6} c_{6}\right) \Delta t \\
\tilde{z}_{k} & =\left(d_{7} c_{7} x\left(t_{k}\right)+d_{8} c_{8} y\left(t_{k}\right)+d_{9} c_{9}\right) \Delta t
\end{aligned}
$$

とおく。

(iii) 点 $(x(0), y(0))$ での現在時刻の降雨強度 $z(x(0), y(0), 0)$ をその点に最も近らメッシュ点の降雨 強度として, $z\left(x_{i}, y_{j}, t_{J}\right)$ を

$$
z\left(x_{i}, y_{j}, t_{J}\right)=z(x(0), y(0), 0)+\sum_{k=1}^{J} \tilde{z}_{k}
$$

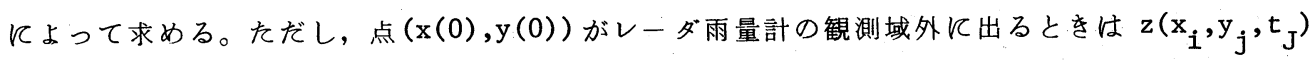
を求めるてとはでをない。とれは移流モデルの意味からして当然である。

\section{3. 発達・衰弱項 wの地点ごとの評価}

レーダ雨量計の観測領域の大きさ(半径百数十 $\mathrm{km}$ 程度) 加らて, 移流べクトル $(\mathrm{u}, \mathrm{v})$ を $\mathrm{x}, \mathrm{y} の 一$ 次式で表わして十分であって, それ以上細かく考える必要はないと思われる。以下では, 発達・衰弱項 について考察する。

大倉ら ${ }^{1)}$ は, 関連係数を用らて移流べクトルを求めた後, その移流べクトルを用的て発達・衰弱項 w を評価するといら方法を提案している。そてで, 本研究でも, 移流べクトルの算定と発達・衰弱項の算 定を切り離して考える方法を追加検討する。

すなわち，すでに述べたパラメタの同定ステップで, $\mathrm{d}_{7}=\mathrm{d}_{8}=\mathrm{d}_{9}=0$ として移流べクトルのパラメタ $c_{1}, \ldots, c_{6}$ を求めた後, それを用いて各地点 $\left(x_{i}, y_{j}\right)$ の発達・衰弱項 $w\left(x_{i}, y_{j}\right)$ を

$$
\begin{gathered}
w\left(x_{i}, y_{j}\right)=\frac{1}{L(k+1)-1} \underset{k=-(L(K+1)-1)}{-1}\left\{\left[\frac{\partial z}{\partial t}\right]+u\left(x_{i}, y_{j}\right)\left[\frac{\partial z}{\partial x}\right]+v\left(x_{i}, y_{j}\right)\left[\frac{\partial z}{\partial y}\right]\right\} \\
u\left(x_{i}, y_{j}\right)=d_{1} c_{1} x_{i}+d_{2} c_{2} y_{j}+d_{3} c_{3} \\
v\left(x_{i}, y_{j}\right)=d_{4} c_{4} x_{i}+d_{5} c_{5} y_{j}+d_{6} c_{6}
\end{gathered}
$$

によって定める。ただし，時間間隔 $\Delta \tau$ を $\Delta t / L(L>0)$ とし， \{\}の中の偏微分項は，(3)，(4)式で $\Delta \mathrm{t} を \Delta \tau$ で置を換えて評価 する(図1参照)。

この場合の降雨予測も2.と同様飞取り扱ってょい。ただ，(11) 式の第 3 式の右辺を, 点 $\left(x\left(t_{k}\right), y\left(t_{k}\right)\right)$ 亿最も近いメッシュ点 の発達・衰弱項で置を換えるだけでよら。

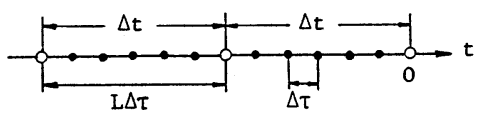

図 $1(\mathrm{u}, \mathrm{v})$ 算定の時間間隔 $\Delta t$ と $\mathrm{w}$ 算定の時間間隔 $\Delta \tau$ の関係

\section{1.適用例とその検討}

4.1 適用データ

梁山レーダ雨量計による台風 8210 MTIデータを用いる。とのレーダ雨量計の定量観測半径は $120 \mathrm{~km}$ とされている。とてでは, $\Delta \mathrm{x}=\Delta \mathrm{y}=7 \mathrm{~km}, \mathrm{M}=\mathrm{N}=40$ の一辺 $280 \mathrm{~km}$ の正方形メッシュ領域をとり, 約 $9 \mathrm{~km}^{2}$ ごとの放射状メッシュの元のデータを雨量強度に変換した後, 正方形メッシュ内で平均化したも のを用いる。データの時間間隔は 5 分である。 


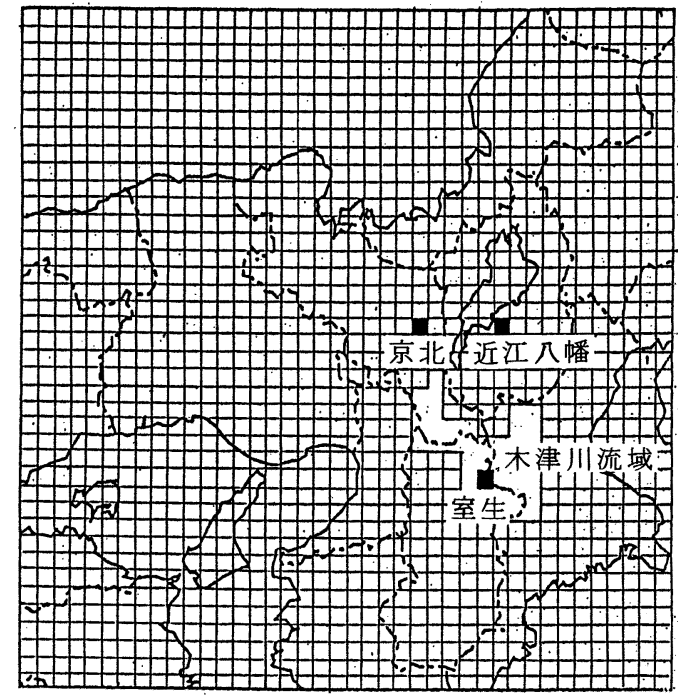

図 2 解析対象領域のメッシュ分割と 木津川流域の位置

\section{2 計算結果とその検討}

ここで示す計算例では, すべて $\Delta t=30$ 分, $K$ $=1$ とした。すなわち, 過去/時間の30分ごとの データを用いて移流べクトル, 発達・衰弱項のパ ラメタを同定する。ただし, 発達・衰弱項を地点 ごとに考える場合は， $\Delta \tau=5$ 分とした。

最初に，(2)式のパラメタを全て組みてんだ結果 を考える。図 3 壮移流べクトルの, 図4 は発達・ 衰弱項の時間変化を, 京北, 近江八幡, 室生(図 2 参照)の3 地点について示したものである。31 日 20 時頃降雨強度の小さいところで異常な移流べ クトルが算出されている他は, 直観とほ后一致す る変化が求められている。このような異常值を防 ぐには, 情報配列 $\mathrm{S}$ の初期值を 0 とせず, 対角成 分にある正の值を入れておくとよい。図 5 は木津 川流域（図 2 参照）の流域時間雨量の/時間先, 2 時間先の予測結果, 図 6 は, 図 2 のメッシ二領 域すべてでの予測の決定係数 $\mathrm{CD}$ (相関係数の 2 乗) 有効性係数 $\mathrm{CE}$, 標準誤差 $\sigma$ の時間変化を全領域平 均降雨強度の時間変化とともに示したるのである

次に, 発達・衰弱項を地点ごとに考える場合に ついて述べる。図 7 は, 移流べクトルを位置の一

次式として同定した後で地点ごとに同定した発達・衰弱項の時間変化を，京北，近江八幡，室生の3地 点について示したものである。発達・衰弱項の值は大をく変動し, 地点でとにも大をく異っている。て れは発達・衰弱項の取扱いが難しいてとを示唆している。実際, 木津川流域の流域時間雨量の予測と実 測の相関係数を示した表 1 で，発達・衰弱項を地点ごとに考えるケースは総体としてよい結果を与えて らないととがわかる。この表には, 移流べクトルを一様とした場合や発達・衰弱項を無視した場合の相
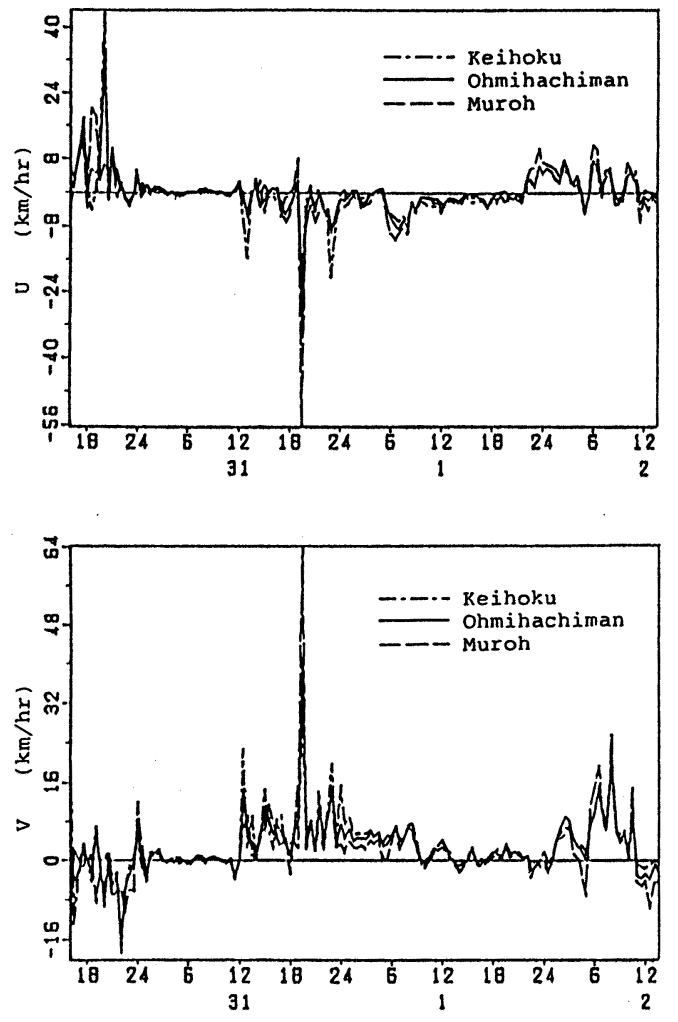

図 3 同定された移流べクトル $(\mathrm{u}, \mathrm{v})$ の時間変化

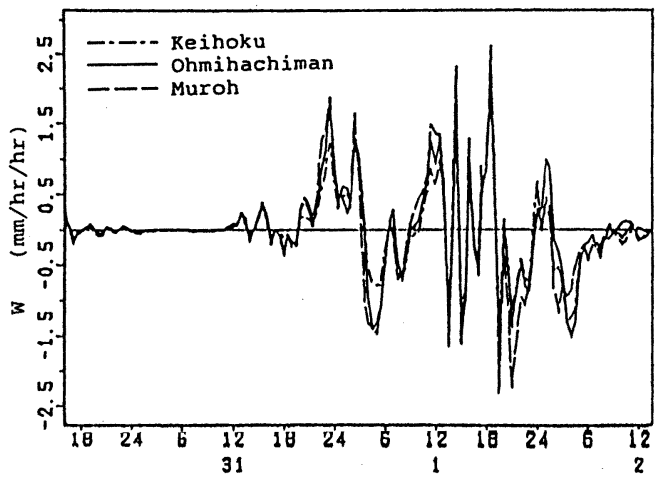

図 4 同定された発達・衰弱項 wの時間変化 

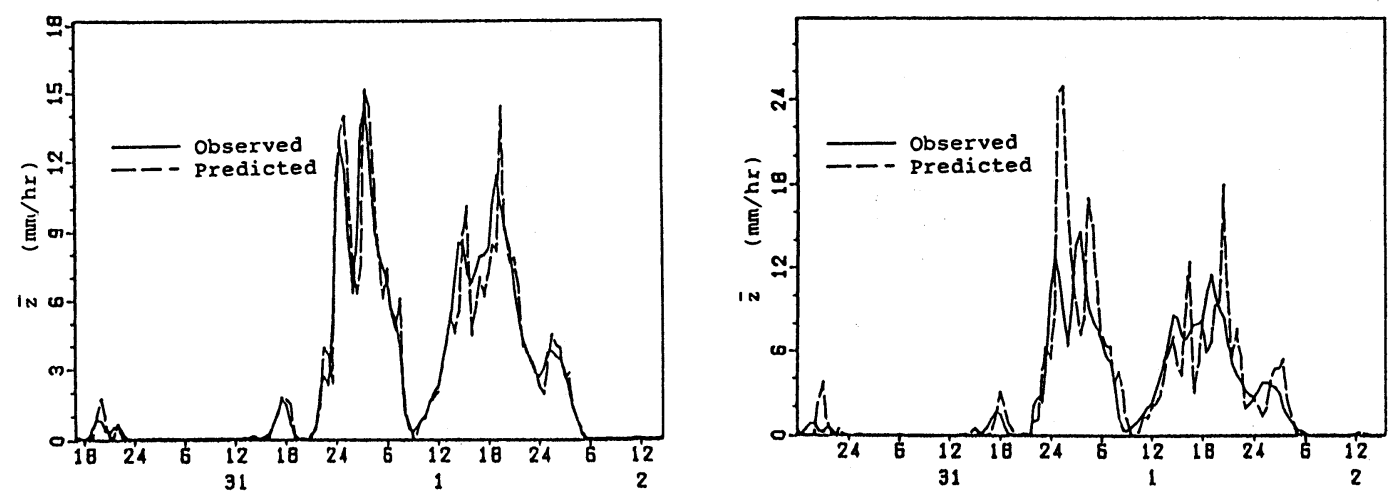

図 5 木津川流域時間雨量の予測值と実測值との比較（左：/時間先, 右：2時間先）
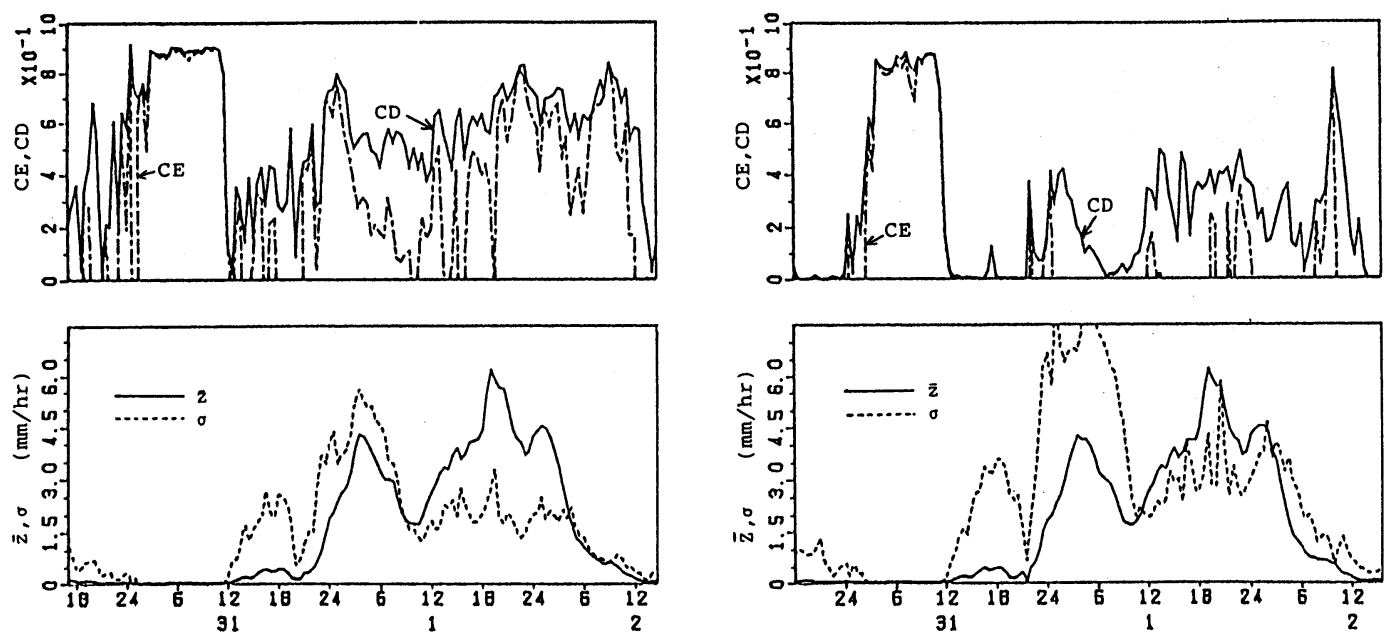

図6 解析対象領域での予測值と実測值の適合度 (左：/時間先, 右：2時間先),

( $\mathrm{CD}$ : 決定係数, $\mathrm{CE}$ : 有効性係数, $\overline{\mathrm{z}}$ : 平均降雨強渡, $\sigma$ : 予測值の標準誤差)

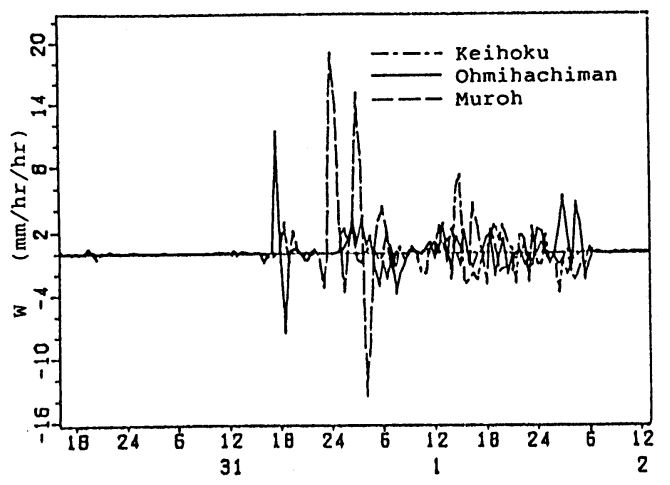

図 $7(\mathrm{u}, \mathrm{v})$ 項を位置の一次式として, 地点 ごとに同定された発達・衰弱項 $\mathrm{w} の$ 時 間変化
表 1 木津川流域時間雨量系列の予測と 実測とす相関係数

\begin{tabular}{|c|c|c|c|c|}
\hline & \multicolumn{3}{|c|}{$\mathrm{U}, \mathrm{V}$ 項 } \\
\hline & & 0 & 一次式 & 一撗 \\
\hline \multirow{3}{*}{$\begin{array}{l}W \\
\text { 項 }\end{array}$} & 0 & $\begin{array}{l}0.948 \\
0.766 \\
0.638\end{array}$ & $\begin{array}{l}0.954 \\
0.794 \\
0.679\end{array}$ & $\begin{array}{l}0.950 \\
0.824 \\
0.747\end{array}$ \\
\hline & 一次式 & $\begin{array}{l}0.944 \\
0.791 \\
0.715\end{array}$ & $\begin{array}{l}0.953 \\
0.798 \\
0.689\end{array}$ & $\begin{array}{l}0.952 \\
0.825 \\
0.741\end{array}$ \\
\hline & 地点 & $\begin{array}{l}8.916 \\
0.672 \\
0.626\end{array}$ & $\begin{array}{l}0.896 \\
0.609 \\
0.576\end{array}$ & $\begin{array}{l}0.926 \\
0.704 \\
0.641\end{array}$ \\
\hline
\end{tabular}

上 段: 1 時間後

中 段: $: 2$ 時間徭 
Appendix A Householder 変換プログラム

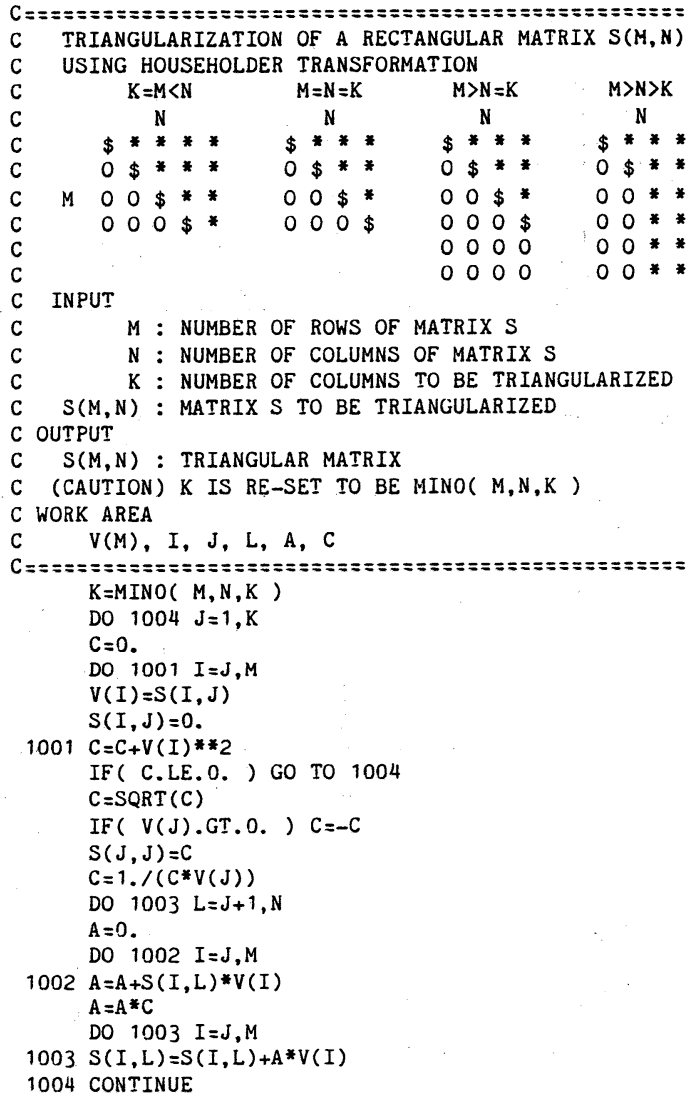

Appendix B 連立一次方程式(9)を解くプログラム

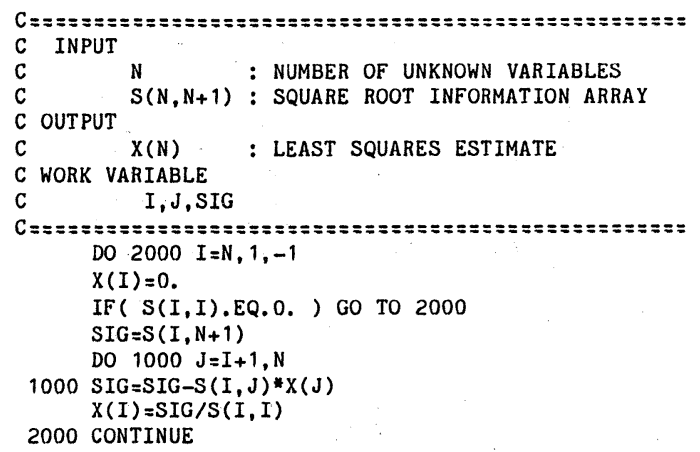

関係数も示している。乙の例だけでは即断でをな レが, 雨域の歪みや回転, 発達・衰弱項は乱れと して扱った方が安定した予測を与えるよらである。

本研究で用いたデータは近畿地方建設局淀川ダ ム統合管理事務所から提供して頂いた。謹んで謝 意を表する。なお, 筆者らの論文7)でも同じデー 夕を用いているが, 同事務所城尾氏の御指摘によ り，データの取扱いに錯誤があるととが判明した。 同氏の御指摘に感謝するととすに，ととで訂正し ておくものである。

\section{参考文献}

1）石崎・中尾・森本 (1980) : レーダ雨量計に よる短時間降雨予測, 第 35回年講.

石崎・中尾・森本 (1981) : レーダ雨量計に よる短時間降雨予测（発達・減衰項の導入）, 第 36 回年講.

大倉・石崎・中尾・森本 (1983) : レーダ雨 量計を用いた短時間降雨予測, 第 27 回水理講演 会論文集.

2）立平・牧野（1974）：デジタル化されたエコ 一パターンの予測への利用, 研究時報 26 巻.

3）竹内（1978）：雨域・雨量強度分布変化の短 時間予測, 第 22 回水理講演会論文集.

4）下垣・室田・江藤（1978）：雨量観測レーダ ーによる降雨量分布の解析とそのオン・ライン 予測, 第 22回水理講演会論文集.

5) Bellon, A. and G.L.Austin (1978) : The evaluation of two years of real-time operation of a short-term precipitation forecasting procedure (SHARP), J.Appl. Meteor., 17, $1778-1787$.

6) Wilk,K.E. and K.C.Gray (1970) : Processing and analysis techniques used with the NSSL weather radar system, Proc. 14th Radar Met. Conf., 369-374.

7）高棹・椎葉・中北（1983）：レーダー雨量計 に上る短時間降雨予測の検討, 京大防災研究所 年報, B-2.

8) G.J.Bierman (1977) : Factorization methods for discrete sequential estiration, Academic Press. 